\title{
Importance-Performance Matrix Analysis of the Factors Influencing International Students' Psychological and Sociocultural Adaptations Using SmartPLS
}

\author{
Completed Research Paper
}

\author{
$\mathbf{1}^{\text {st }}$ Azadeh Shafaei \\ School of Educational Studies, \\ Universiti Sains Malaysia (USM) \\ Penang 11800, Malaysia
}

\author{
$2^{\text {nd }}$ Nordin Abd Razak \\ School of Educational Studies, \\ Universiti Sains Malaysia (USM) \\ Penang 11800, Malaysia
}

\begin{abstract}
With the increase in international mobility in higher education especially in Asia, the issue of cross-cultural adaptation becomes paramount since international students try to overcome challenges and flourish psychologically and socioculturally in a new environment. Therefore, this study is conducted to identify the factors influencing international postgraduate students' psychological and sociocultural adaptations in Malaysian public universities, an emerging education hub in the region. It also further investigates importance-performance matrix analysis (IPMA) of the antecedents for psychological and sociocultural adaptations as the endogenous variables to provide insights and derive recommendations for education policymakers and academic administrators to ensure successful international postgraduate students' cross-cultural adaptation.
\end{abstract}

Keywords: Cross-cultural adaptation, psychological adaptation, sociocultural adaptation, Importance-Performance Matrix Analysis (IPMA), internationalization of higher education

\section{Introduction}

International students mobility has become an important aspect of the global education for more than 10-15 years (Verbik \& Lasanowski, 2007). It is worth noting that international students' mobility to other countries for the purpose of getting the best education can contribute significantly to the financial, social, cultural and academic growth of the host countries. Thus, governments have paid notable attention to education internationalization in order to grow their countries economic by making improvements in universities academic work and national development (Porter \& Vidovich, 2000). This fact has led to a worldwide competition among educational institutions to develop knowledge-based economy through training the best brains especially in Asia (Arokiasamy, 2010).

Malaysia is one of these countries emerged to be an education hub in the region (Verbik \& Lasanowski, 2007). UNESCO has ranked Malaysia as the $11^{\text {th }}$ country in the world by holding 2.5\% of global international students (Ministry of Higher Education Malaysia, 2009). According to the statistics, 80,750 international students enrolled in Malaysian universities in 2009 while this number increased to 111,939 in 2011 (Cheng, Mahmood, \& Yeap, 2013). Education internationalisation not only develops the global knowledge network but it also grows business in Malaysia (Cheng et al., 2013). Particularly, education sector in Malaysia contributed 4 per cent to the Malaysian Gross National Income (GNI) and it is expected to be doubled by 2020 (PEMANDU, 2010). 
Apart from the economic growth and benefits of education mobility for Malaysia, challenges to adjust to a new culture together with rigorous academic demands might put international students at the risk of challenging and stressful adjustment. Dissimilarity between the international students' ethnic culture norms and the new culture (Yang \& Clum, 1994) and lack of knowledge about new cultural norms and values often leads to a significant amount of life stress for international students which can bring about negative consequences for international students as well as the host society (Sumer, 2009). Nonetheless, if international students overcome their difficulties and problems, they can successfully adapt to the new environment and the negative consequences of norms and its related stereotypes would be avoided (Molinsky, 2007). Consequently, tremendous attention has been paid to the issue of cross-cultural adaptation by researchers in various contexts. Review of the existing literature on cross-cultural adaptation shows that the emphasis of the researchers has been on the identification of crucial factors which could facilitate or hinder the process of individuals' adaptation to a new cultural environment (e.g., Li \& Gasser, 2005; Tonsing, 2013). However, further examination of the factors influencing cross-cultural adaptation considering the importance and performance of each factor has remained relatively unexplored in the literature.

In an effort to identify the factors influencing international postgraduate students' crosscultural adaptation, this study aims to empirically examine the relationship between several individual factors (i.e. English language proficiency, and acculturation attitude) and situational factors (i.e. perceived social support, and perceived stereotype image) with international postgraduate students' psychological and sociocultural adaptations in Malaysian public universities. Besides, identifying and investigating the crucial factors influencing international postgraduate students' cross-cultural adaptation in Malaysia through measuring the importance and performance of each factor with the criterions of psychological and sociocultural adaptations provides practical, managerial and empirical contributions.

\section{Cross-Cultural Adaptation}

Since the focus of this study is to provide empirical insights about the factors influencing cross-cultural adaptation, first the conceptualization of cross-cultural adaptation is discussed followed by its antecedents namely; individual factors and situational factors.

The notion of cross-cultural adaptation refers to the dynamic change process which occurs to individuals when they move to a new environment (Kim, 2001). Particularly, functional fitness, psychological health and intercultural identity development are the three facets of cross-cultural adaptation (Kim, 2001). Similarly, based on the definition suggested by Ward and colleagues cross-cultural adaptation refers individuals' psychological and sociocultural adaptation to a new society (Ward \& Kennedy, 1994). Accordingly, the two terms proposed by Ward and colleagues as psychological adaptation and sociocultural adaptation respectively coincide with psychological health and functional fitness proposed by Kim (Wang \& Sun, 2009). These two mentioned concepts have been the basis to measure cross-cultural adaptation in most of the prior relevant studies (e.g., Li \& Gasser, 2005; Tonsing, 2013)

\subsection{Psychological adaptation}

Psychological adaptation has been largely referred to as internal psychological state of the individual and individuals' ability in handling life stressor which results in negative and positive consequences (Lazarus \& Folkman, 1984). The negative effect of psychological adaptation would be depression, social alienation, identity confusion, anxiety and psychosomatic symptoms (Berry \& Sam, 1997). However, clear sense of personal and 
cultural identity, high self-esteem, good mental health, and the attainment of efficient cultural and social skills are considered as the positive effects of psychological adaptation (Sumer, 2009). Unlike common existing conceptualizations, Tonsing (2013) defined psychological adaptation as both psychological distress and life satisfaction because the absence or presence of the psychological distress does not necessarily mean life satisfaction and vice versa. Therefore, in this study psychological adaptation refers to international postgraduate students' ability in coping with psychological distress caused to them in a new environment as well as their satisfaction with life and their self-esteem in Malaysia in line with Tonsing's (2013) suggestion.

\subsection{Sociocultural adaptation}

Sociocultural adaptation is mainly defined as the external and objective psychological outcome that links individuals to their new context, such as the ability to deal with daily problems especially family life, work and school and the ability to "fit in" the new culture (Ward \& Kennedy, 1999). Since the notion of sociocultural adaptation refers to the various skills of individuals to manage personal and social life in a new environment with less difficulty, this study, in line with the previous studies, operationalizes sociocultural adaptation as the international postgraduate students' ability to handle daily life and fit into Malaysian society.

\section{Antecedents of Cross-Cultural Adaptation}

According to Lewin's field theory (Lewin, 1951), a person's behaviours occur within a psychological field which is called the 'life-space' (Schultz \& Schultz, 2004). The 'life-space' refers to every forces in the field both from the inner and outer environment that shapes up the individual such as the places an individual goes, the people the individual meets and the feelings the individual has about the places or people. As Lewin believed understanding the relations of all factors in one's life-space is crucial because those are the elements which play important roles in helping or blocking people from accommodating to the new environment (Sorrentino, 2013). Therefore, Lewin (1951) proposed the equation for life-space as " $\mathrm{B}=\mathrm{f}(\mathrm{P}$, E)" which indicates that the individuals' behaviour (B) can be explained by considering both the person $(\mathrm{P})$ and their environment $(\mathrm{E})$. The environment here does not refer to the physical environment but the psychological environment perceived by the person (Sorrentino, 2013). Additionally, the person and the environment are interdependent and that creates a dynamic and complex field of interaction which help individuals learn more about themselves and their environment (Daniels, 2003). Therefore, Lewin (1951) regarded the field as a continuous state of adaptation. In convergence with the concepts of the filed theory the antecedents of crosscultural adaptation have been categorized as the individual and situational factors.

\subsection{Individual factors}

The individual factors refer to the person related factors which is defined as general life situation in Lewin's (1951) field theory. It generally includes a person's psychological lifespace and background factors (Chak, 2002). Furthermore, every factor which is related to the person or individual decision in facilitating cross-cultural adaptation is categorized as the individual factors.

\subsubsection{English language proficiency}

Language is a vital tool in learning and acquiring new cultural skills and also one of the key elements in adaptation process. To interact with local people in the host country and to 
better understand local culture and values, international students need to have a good command of language proficiency (Mahmud, Amat, Rahman, \& Ishak, 2010). Kim (1988) mentioned that the factor of effective social communication is believed to be the key of successful adaptation and this communication is done through language. According to Ward (2004, p. 190) "Language skills are important because they affect the quality and quantity of intercultural interactions". Thus, it is hypothesized:

H1: English language proficiency positively influences international postgraduate students' psychological adaptation.

H2: English language proficiency positively influences international postgraduate students' sociocultural adaptation.

\subsubsection{Acculturation attitude}

The conflict between preserving the ethnic identity (keep) and developing a new identity consistent with the norms and behaviours of host society (adopt) has always been an important issue for immigrants and sojourners (Berry, Segall, \& Kagitcibasi, 1999). Based on the evidence from earlier studies, having any of keep or adopt attitudes can influence individuals' adaptation differently. For example, higher psychological and sociocultural adaptations are related to both keep and adopt, but higher sociocultural adaptation is related to adopt (Ward \& Kennedy, 1994). Moreover, through communicating with the host nationals, individuals improve their quality of interaction and learn more about the new environment which facilitates better cross-cultural adaptation. Therefore, it is hypothesized:

H3: Adjustment attitude significantly influences international postgraduate students' psychological adaptation.

H4: Adjustment attitude significantly influences international postgraduate students' sociocultural adaptation.

H5: Attachment attitude significantly influences international postgraduate students' psychological adaptation.

H6: Attachment attitude significantly influences international postgraduate students' sociocultural adaptation.

\subsection{Situational factors}

Situational factors are defined as the factors which are at the environmental level. In Lewin's (1951) field theory, it refers to the perceived psychological environment. In other words, it refers to the individuals' perception of their psychological environment.

\subsubsection{Perceived social support}

Social support is defined as the support networks of co-national and host national friends that are formed by sojourners in order to manage academic, social and emotional problems (Alazzi \& Chiodo, 2006). There are three main sources of social support (i.e. family, friends and others) (Chirkov, Safdar, De Guzman, \& Playford, 2008). In the case of international students, others include university staffs, academic staffs, international office, international students club and academic services and the larger community are also important to provide support because international students might approach them when they face challenges or difficulties (Zhou, Frey, \& Bang, 2011). Additionally, higher levels of anxiety and depression are associated with lack of social support (Sumer, Poyrazli, \& Grahame, 2008). Hence, social support is an important determinant of cross-cultural adaptation by reducing stress and anxiety and increasing international students' knowledge and understanding of the host culture (Safdar, Struthers, \& van Oudenhoven, 2009). Accordingly, the following hypotheses are advanced: 
H7: Social support provided from different sources (family, friends and university academic and non-academic staffs) positively influences international postgraduate students' psychological adaptation.

H8: Social support provided from different sources (family, friends and university staffs) positively influences international postgraduate students' sociocultural adaptation.

\subsubsection{Perceived stereotype image}

Stereotype is defined as individuals' beliefs about members of some social groups which involves generalizations about their typical characteristics (Jussim, Nelson, Manis, \& Soffin, 1995). It also refers to people's social categorical judgment of the members of other groups (Hean, 2009). The stereotype made in a country by the dominant group can significantly influence the stereotyped groups' behaviours and attitudes (O'Sullivan \& Durso, 1984). In line with the social identity theory, the stereotype image can result in positive or negative relations with the host nationals which can affect sociocultural adaptation (Tajfel \& Turner, 1986). Additionally, negative stereotype could increase individuals' stress and anxiety which can affect individuals' psychological health and ultimately result in unsuccessful psychological adaptation. Thus, it is hypothesized:

H9: Perceived stereotype image can significantly influence international postgraduate students' psychological adaptation.

H10: Perceived stereotype image can significantly influence international postgraduate students' sociocultural adaptation.

Considering the equation of life-space in the field theory which emphasizes the role of individual and situational factors, the proposed model in this study is developed. As shown in Figure 1, individual and situational factors are the exogenous variables which influence international postgraduate students' psychological and sociocultural adaptations (i.e. endogenous variables).

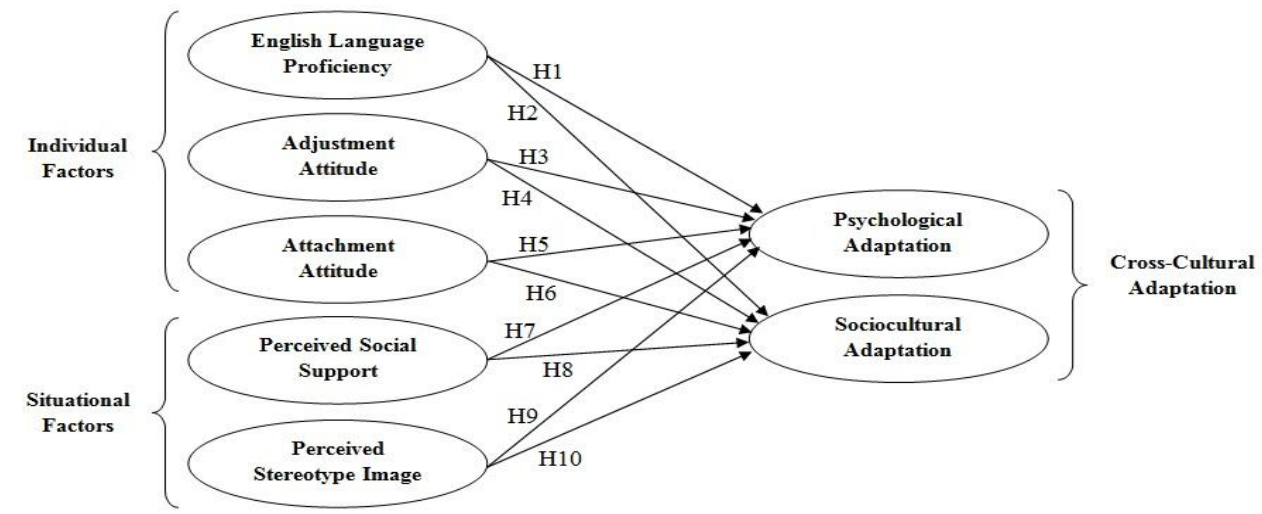

Figure 1: Research Model

\section{Design of the Empirical Study}

An online questionnaire, validated through pilot test, was emailed to all the postgraduate students (i.e. 5372) in Malaysian public universities. To ensure the ethical considerations in this study, the purpose of the study was explained clearly in the email sent to each international postgraduate student. The participants were also ensured that all their responses would remain anonymous and confidential and the information provided from them would be merely used for the purpose of the research. The questionnaire was in English, as the medium of instruction is English for international students in Malaysian universities. The responses of 
the participants were recorded on a 6-point Likert scale. Table 1 illustrates the instruments measurement scales adapted to measure each construct, number of items, the measurement model and the sources of the scales.

Table 1: Constructs Measurement Scales

\begin{tabular}{|c|c|c|c|c|}
\hline Construct & Instrument & $\begin{array}{c}\text { Number of } \\
\text { Items Adapted }\end{array}$ & $\begin{array}{c}\text { Measurement } \\
\text { Model }\end{array}$ & Source \\
\hline $\begin{array}{l}\text { English } \\
\text { Language } \\
\text { Proficiency }\end{array}$ & $\begin{array}{c}\text { Language Proficiency Scale } \\
\text { ELP }\end{array}$ & ELP: 4 items & Reflective & - Kwak (1991) \\
\hline $\begin{array}{l}\text { Adjustment } \\
\text { Attitude }\end{array}$ & Adopt Scale & AdjA: 5 items & Reflective & $\begin{array}{l}\text { Swaidan, Vitell, Rose, } \\
\text { and Gilbert (2006) }\end{array}$ \\
\hline $\begin{array}{l}\text { Attachment } \\
\text { Attitude }\end{array}$ & Keep Scale & AttA: 5 items & Reflective & Swaidan et al. (2006) \\
\hline $\begin{array}{l}\text { Social } \\
\text { Support }\end{array}$ & $\begin{array}{l}\text { Multidimensional Scale of } \\
\text { Perceived Social Support } \\
\text { (MSPSS) }\end{array}$ & MSPSS: 9 items & Formative & $\begin{array}{l}\text { Zimet, Dahlem, Zimet, } \\
\text { and Farley (1988) }\end{array}$ \\
\hline $\begin{array}{l}\text { Perceived } \\
\text { Stereotype } \\
\text { Image }\end{array}$ & Stereotype Image Scale & PSI: 5 items & Reflective & (Carpenter, 1995) \\
\hline $\begin{array}{l}\text { Psychological } \\
\text { Adaptation }\end{array}$ & $\begin{array}{l}\text { - Depression Anxiety and } \\
\text { Stress Scale (DASS) } \\
\text { - Life Scale (SWLS) } \\
\text { - Self-Esteem Scale (SES) }\end{array}$ & $\begin{array}{l}\text { DASS: } 6 \text { items } \\
\text { (Depression) } \\
\text { SWLS: } 5 \text { items } \\
\text { SES: } 6 \text { items }\end{array}$ & Formative & $\begin{array}{l}\text { - Lovibond and } \\
\text { Lovibond (1995) } \\
\text { - Diener, Emmons, } \\
\text { Larsen, and Griffin } \\
\quad(1985) \\
\text { - Rosenberg (1965) }\end{array}$ \\
\hline $\begin{array}{l}\text { Sociocultural } \\
\text { Adaptation }\end{array}$ & $\begin{array}{c}\text { Sociocultural Adaptation } \\
\text { Scale (SCAS) }\end{array}$ & SCAS: 10 items & Reflective & $\begin{array}{l}\text { Ward and Kennedy } \\
\text { (1999) }\end{array}$ \\
\hline
\end{tabular}

Among the emails sent to the international postgraduate students, total of 1023 responses were received; however 818 of them were included in this study since they were fully completed. The participants of this study included 818 international students enrolled in a postgraduate level (i.e. master or $\mathrm{PhD}$ ) in the public universities in Malaysia. Specifically, $42 \%$ of the participants were master students while $58 \%$ were $\mathrm{PhD}$ students. About $68 \%$ of the participants were male while $32 \%$ female. The largest group of participants were in the age group of 25-30 years old (37\%), followed by the 31-35 age group (27\%). Besides, $8 \%$ of respondents were below 25 years old. Among the participants, 57\% were married. Participants came mainly from the two Asia (48\%) and Middle East (31\%) with 22\% from Africa.

\subsection{Assessment of the path model}

The research model was tested through Partial Least Square path modelling technique using SmartPLS version 3.0 (Ringle, Wende, \& Becker, 2014) due to two main reasons; (a) this study is exploratory in nature, and (b) there are formative constructs in the research model. Thus, this technique is appropriate, since the hypothesized relationships among the variables have not been tested before, indicating the exploratory nature of the research (Ainuddin, Beamish, Hulland, \& Rouse, 2007). Moreover, given the perceived difficulties in formative models, the most suitable and capable technique in handling both formative and reflective constructs in a research model is SmartPLS (Hair, Black, Babin, \& Anderson, 2010).

A two-step process was applied; outer model assessment (i.e. measurement model) and the inner model assessment (i.e. structural model) in SmartPLS version 3.0 (Henseler, Ringle, \& Sinkovics, 2009). The measurement model is concerned with the assessment of reliability and validity of the variables while the structural model evaluates the significance of the path coefficients in the research model. Figure 2 presents the path model in SmartPLS. 


\subsubsection{Assessment of the reflective measurement model}

For the reflective measurement model assessment, item loadings, average variance extracted (AVE), composite reliability (CR) were assessed for the following constructs; 'English language proficiency', 'adjustment attitude', 'attachment attitude', 'perceived stereotype image' and 'sociocultural adaptation'. Factor loadings are above the ideal threshold of 0.70 except for a few items which fall below 0.70 (i.e. above 0.603 ); however, they do not cause any problem and the fit remains high, and the average variance extracted (AVE) of all the reflective constructs are above the threshold of 0.5 (Fornell \& Larcker, 1981; Hair et al., 2010). Besides, composite reliability indices of all the constructs are close to 0.9 which is higher than the cut-off value of 0.7 (Hair, Black, Babin, Anderson, \& Tatham, 2009) indicating satisfactory reliability.

In addition, the discriminant validity of the reflectively measured constructs was assessed using the heterotrait-monotrait ratio (HTMT) proposed by Henseler, Ringle, and Sarstedt (2015). Since Fornell and Larcker (1981) criterion and cross loadings are insufficiently sensitive to detect problems with discriminant validity, it is suggested to assess the heterotraitmonotrait ratio (HTMT) of the correlations that refers to the average of the heterotraitheteromethod correlations (i.e., the correlations of indicators across constructs measuring different phenomena), relative to the average of the monotrait-heteromethod correlations (i.e., the correlations of indicators within the same construct) (Henseler et al., 2015). All the values of HTMT are below the threshold of 0.85 (Clark \& Watson, 1995; Kline, 2011) confirming the establishment of discriminant validity of the reflectively measured constructs.

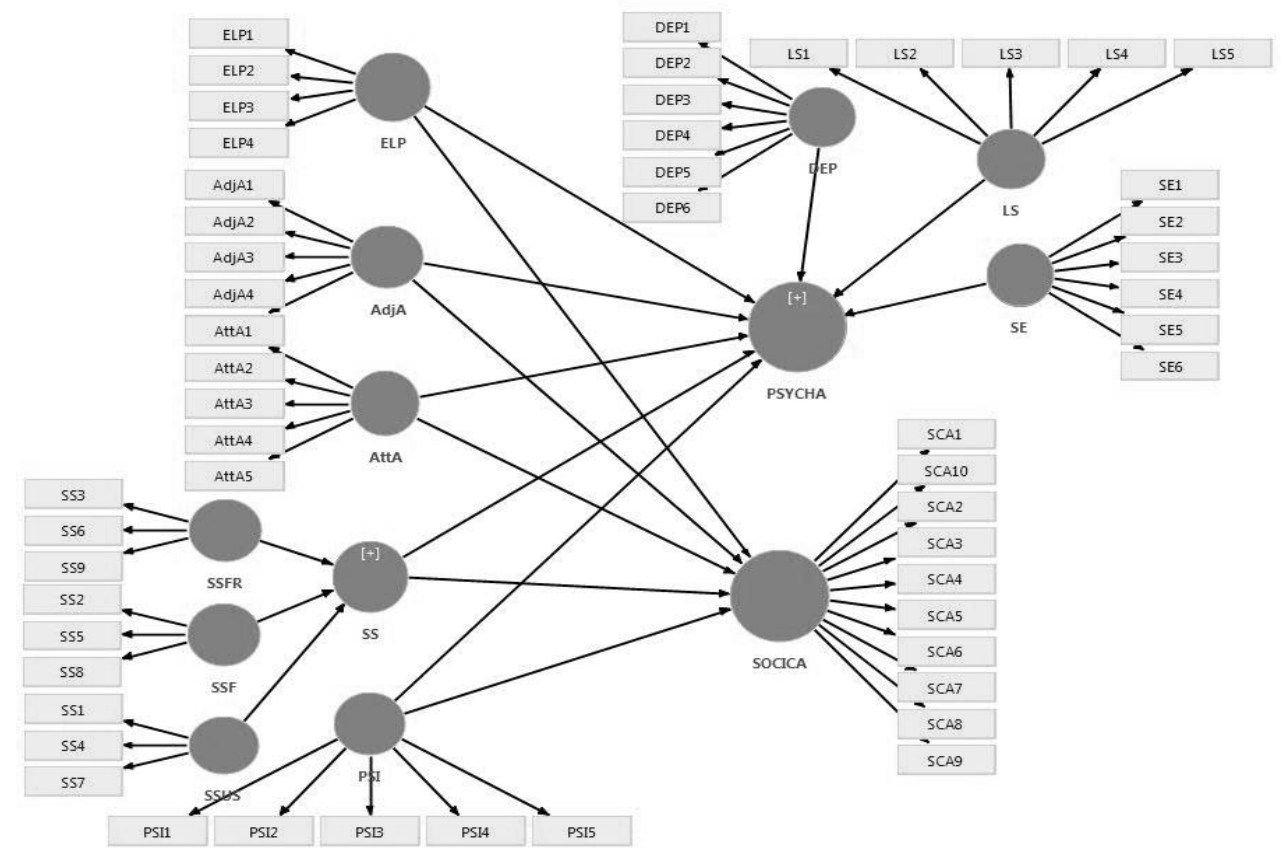

Figure 2: Path Model

\subsubsection{Assessment of the formative measurement model}

For the formative measurement model, weight significance of each indicator and multicollinearity (variance inflation factor VIF) were assessed for 'psychological adaptation (PSYCHA)' and 'social support (SS)'. All the indictors' weights are significant (two-sided $p$ <0.01) [PSYCHA: (depression, weight: 0.430, t-value: 27.23; life satisfaction, weight: 0.378, t-value: 23.72 ; self-esteem, weight: 0.488 , t-value: 27.65 ) and SS: (social support from family, weight: 0.273 , t-value: 8.73 ; social support from friends, weight: 0.414 , t-value: 31.35; social support from university staffs, weight:0.627, t-value: 19.41)]. Additionally, the highest VIF values for both formative constructs' indicators is 1.845 which is below the cutoff value of 3 suggested by Hair et al. (2009) confirming that multi-collinearity is not a 
problem. Overall, both reflective and formative measurement models are confirmed before assessing the structural model.

\subsubsection{Assessment of the structural model}

For assessing the structural model, repeated indicator approach (Lohmöller, 1989) was applied since there are two reflective-formative constructs in the research model (i.e., social support an exogenous variable and psychological adaptation an endogenous variable). Due to having a formative hierarchical latent variable in an endogenous position (i.e. psychological adaptation) using all the three approaches (i.e. two-stage, repeated and hybrid) are suitable (Becker, Klein, \& Wetzels, 2012). Besides, the essential criterion to assess the structural model is the coefficient determination of $\mathrm{R}$ square $\left(\mathrm{R}^{2}\right)$. For 'psychological adaptation' and 'sociocultural adaptation' the $\mathrm{R}$ square values are 0.310 and 0.344 respectively which lie at the satisfactory range since in studying human behaviour (e.g., psychology) $R$ square value is lower than 50\% (Frost, 2013). The inner model path analysis shows that among the 10 hypotheses advanced in this study, only one (i.e. AttA $\rightarrow$ PSYCHA) is not supported. In particular, the paths between AdjA $\rightarrow$ PSYCHA, AdjA $\rightarrow$ SOCICA, AttA $\rightarrow$ SOCICA, ELP $\rightarrow$ PSYCHA, ELP $\rightarrow$ SOCICA, PSI $\rightarrow$ PSYCHA, PSI $\rightarrow$ SOCICA, SS $\rightarrow$ PSYCHA, SS $\rightarrow$ SOCICA are all statistically significant at $p<0.05$ confidence level (One-sided) and thus the respective hypotheses are supported.

\subsection{Importance-performance matrix analysis}

In the last step, the analysis of importance-performance matrix of path modelling was carried out in order to identify the possible areas that need to be addressed and improved with management activities. Specifically, by assessing IPMA the impact of latent variables with a relatively high importance and relatively low performance on a particular endogenous latent variable would be identified (Hock, Ringle, \& Sarstedt, 2010). Subsequently, IPMA results provide managerial insights to address and improve the identified areas with high importance and low performance (Hock et al., 2010; Schloderer, Sarstedt, \& Ringle, 2014). Table 2 illustrates the results of IPMA and Figure 3 visualizes the IPMA results for the two criterions of 'psychological adaptation' and 'sociocultural adaptation'.

Table 2: IPMA Results

\begin{tabular}{ccccc}
\hline \multirow{2}{*}{ Latent Variable } & \multicolumn{2}{c}{ Psychological Adaptation } & \multicolumn{2}{c}{ Sociocultural Adaptation } \\
\cline { 2 - 5 } & $\begin{array}{c}\text { Total Effect } \\
\text { (Importance) }\end{array}$ & $\begin{array}{c}\text { Index value } \\
\text { (Performance) }\end{array}$ & $\begin{array}{c}\text { Total Effect } \\
\text { (Importance) }\end{array}$ & $\begin{array}{c}\text { Index value } \\
\text { (Performance) }\end{array}$ \\
\hline English Language Proficiency & 0.130 & 71.903 & 0.124 & 71.903 \\
Adjustment Attitude & 0.155 & 68.221 & 0.214 & 68.221 \\
Attachment Attitude & 0.029 & 73.525 & -0.074 & 73.525 \\
Social Support & 0.268 & 58.221 & 0.158 & 58.221 \\
Perceived Stereotype Image & 0.209 & 69.897 & 0.328 & 69.897 \\
\hline
\end{tabular}

It is evident from the importance-performance analysis map that for both criterions (i.e. psychological adaptation and sociocultural adaptation) the two highest performances belong to attachment attitude and English language proficiency. However, the variables with the highest importance for psychological and sociocultural adaptations are different. For psychological adaptation, the top three important variables are social support, perceived stereotype image and adjustment attitude with the lowest performance in social support. On the other hand, for sociocultural adaptation, the top three priorities belong to perceived stereotype image, adjustment attitude and social support with the lowest performance in social support. It is worth noting here that, although the three variables show the highest importance for both criterions, their order for each criterion is different. Specifically, for psychological 
adaptation, social support is the most important variable while for sociocultural adaptation perceived stereotype image is the highest priority. Overall, the three most important variables for both psychological and sociocultural adaptations are social support, perceived stereotype image and adjustment attitude.

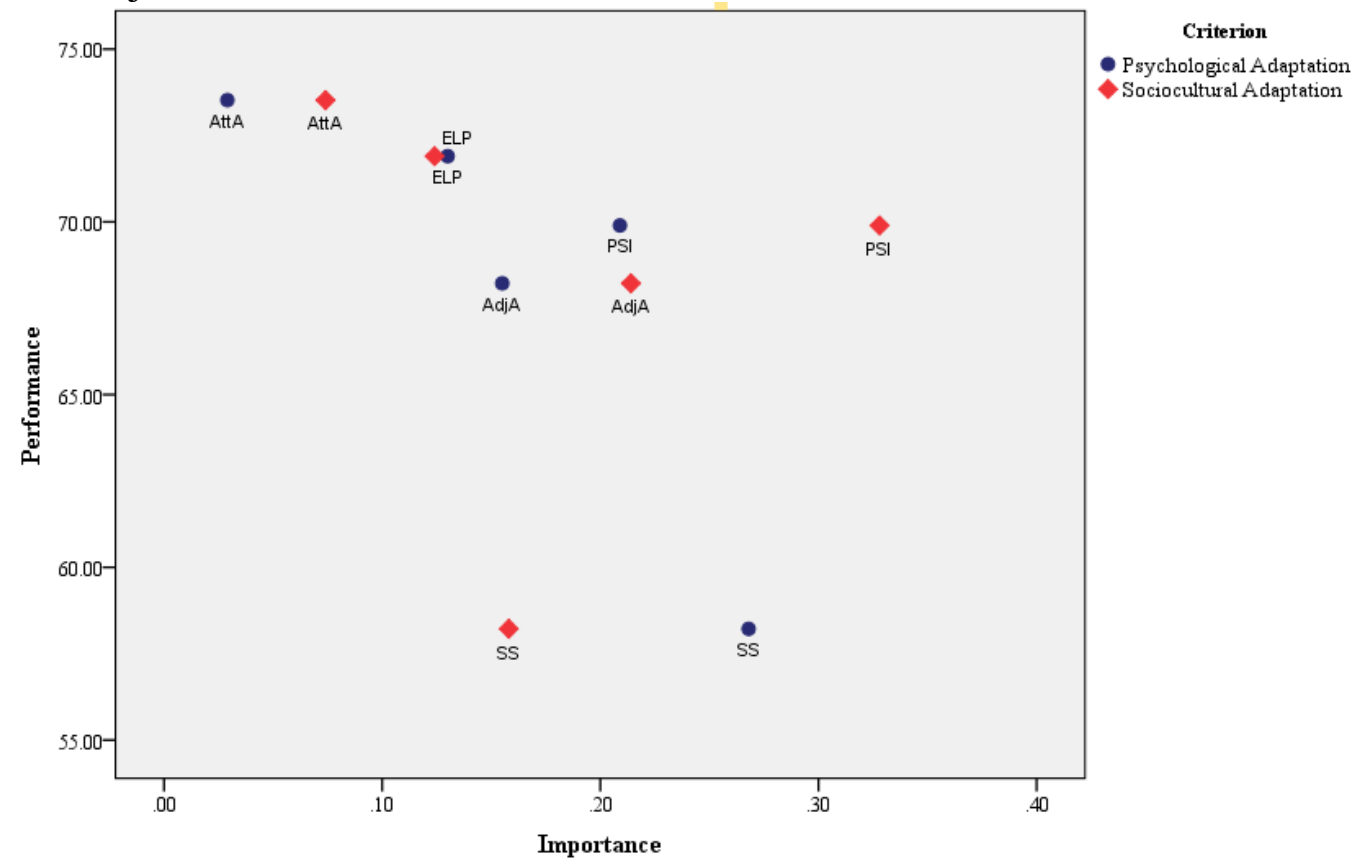

Figure 3: Importance-Performance Matrix Analysis Map

\section{Findings and Conclusions}

Further investigation into the path model analysis using importance and performance of the identified exogenous variables with the criterions of psychological and sociocultural adaptations suggests practical insights about the vital areas which need improvement with regards to international postgraduate students. Particularly, social support is the most important factor for international postgraduate students to be psychologically adapted to the Malaysian environment while perceived stereotype image is highest priority for them to achieve better sociocultural adaptation in Malaysian context. This is understandable since social support acts as a buffer against the stress or challenges faced by international students (Lee \& Ciftci, 2014) and as proven in several prior studies, social support from host-nationals reduces individuals' stress while is leads to psychological well-being and adaptation (Furnham \& Shiekh, 1993). Additionally, stereotype image as the positive or negative beliefs about some members of a society, influences their interaction. As Cooley (1992), the American sociologist, introduced the looking-glass self-concept that refers to the process of person's self-growth through society's interpersonal interactions and the perceptions of others. Thus, people's success in any society is very much associated with their neighbours' and equals' favour and their good opinion which is stereotype image or reputation. Consequently, the stereotypes which are formed in the society can lead to positive or negative reflections in interactions with host nationals that influence sociocultural adaptation.

Therefore, it is the responsibility of the countries that accept international students to understand and address the key variables influencing cross-cultural adaptation process in order to ensure international students can flourish and bring about social, cultural and financial benefits to their academic institutions and countries. Since this study identifies social support, perceived stereotype image and adjustment attitude as the most important variables which need to be considered and addressed with regards to international postgraduate 
students, it can provide valuable practical and managerial implications for the education policymakers as well as academic administrators. Rather than academic and administrative support, international students need psychological and emotional support in the host countries. Particularly, international offices in each university can provide a support network for the international students by listening to their problems and guiding them on how to solve them promoting better psychological adaptation. Besides, host nationals especially university staffs by equally treating international students from different countries can help minimize the threat of stereotyping or discriminating which is a crucial factor for achieving sociocultural adaptation. Additionally, by organizing more cultural events, where international students can learn about the host and other countries' cultures, adjustment attitude will be promoted leading to both psychological and sociocultural adaptations. As a result, focusing on the three mentioned variables is the stepping stone for the Malaysian authorities in the education sector to pave the way towards a brighter prospect in being an education hub in the region by attracting more international students.

The findings of this study have empirical contributions by employing importanceperformance matrix analysis to further investigate and interpret the variables of cross-cultural adaptation in the context of international students. This paper not only examined the relationships between the antecedents and cross-cultural adaptation of international students, but it also further determined among the significantly supported variables which one possesses the highest priority to be focused on. By shedding some light on the application of IPMA in the areas of education and psychology, new directions for future studies will be opened up. The study considered international postgraduate students from public universities in Malaysia; therefore, the findings cannot be generalized to the private universities or other countries. Due to the diverse nature of cross-cultural studies, other antecedents might be identified concerning different groups of people such as migrants, refugees, and expatriates.

Acknowledgment: Azadeh Shafaei is a recipient of USM Global Fellowship.

\section{References}

Ainuddin, R. A., Beamish, P. W., Hulland, J. S., \& Rouse, M. J. (2007). Resource attributes and firm performance in international joint ventures. Journal of World Business, 42(1), 47-60.

Alazzi, K., \& Chiodo, J. J. (2006). Uncovering Problems and Identifying Coping Strategies of Middle Eastern University Students. International Education, 35(2), 65-81.

Arokiasamy, A. R. A. (2010). The Impact of Globalization on Higher Education in Malaysia. Retrieved 20 January, 2015, from http://www.nyu.edu/classes/keefer/waoe/aroka.pdf

Becker, J.-M., Klein, K., \& Wetzels, M. (2012). Hierarchical latent variable models in PLS-SEM: guidelines for using reflective-formative type models. Long Range Planning, 45(5), 359-394.

Berry, J. W., \& Sam, D. L. (1997). Acculturation and adaptation. In J. W. Berry, M. H. Segall \& Ç. Kağıtçıbaş1 (Eds.), Handbook of cross-cultural psychology (Vol. 3 Social behavior and applications, pp. 291-326). Boston, MA: Allyn \& Bacon

Berry, J. W., Segall, M. H., \& Kagitcibasi, C. (1999). Handbook of Cross-cultural Psychology Social behavior and applications. Boston: Allyn \& Bacon.

Carpenter, J. (1995). Doctors and nurses: stereotypes and stereotype change in interprofessional education. Journal Of Interprofessional Care, 9(2), 151-161.

Chak, A. (2002). Understanding children's curiosity and exploration through the lenses of Lewin's field theory: on developing an appraisal framework. Early Child Development and Care, 172(1), 77-87.

Cheng, M. Y., Mahmood, A., \& Yeap, P. F. (2013). Malaysia as a regional education hub: a demandside analysis. Journal of Higher Education Policy and Management, 35(5), 523-536.

Chirkov, V., Safdar, S., De Guzman, J., \& Playford, K. (2008). Further examining the role motivation to study abroad plays in the adaptation of international students in Canada. International Journal of Intercultural Relations, 32(5), 427-440. 
Clark, L. A., \& Watson, D. (1995). Constructing validity: Basic issues in objective scale development. Psychological assessment, 7(3), 309.

Cooley, C. H. (1992). Human nature and the social order. New York: Transaction Publishers.

Daniels, V. (2003). Kurt Lewin Notes. Retrieved 20 September, 2013, from http://www.sonoma.edu/users/d/daniels/lewinnotes.html

Diener, E., Emmons, R. A., Larsen, R. J., \& Griffin, S. (1985). The satisfaction with life scale. Journal of personality assessment, 49(1), 71-75.

Fornell, C., \& Larcker, D. F. (1981). Evaluating structural equation models with unobservable variables and measurement error. Journal of marketing research, 18(1), 39-50.

Frost, J. (2013). Regression Analysis: How Do I Interpret R-squared and Assess the Goodness-of-Fit? Retrieved 15 January, 2015 http://blog.minitab.com/blog/adventures-in-statistics/regressionanalysis-how-do-i-interpret-r-squared-and-assess-the-goodness-of-fit

Furnham, A., \& Shiekh, S. (1993). Gender, generational and social support correlates of mental health in Asian immigrants. International Journal of Social Psychiatry, 39(1), 22-33.

Hair, J. F., Black, W. C., Babin, B. J., \& Anderson, R. E. (2010). Multivariate Data Analysis (7th ed.). New Jersey: Pearson Prentice Hall Inc.

Hair, J. F., Black, W. C., Babin, B. J., Anderson, R. E., \& Tatham, R. L. (2009). Multivariate Data Analysis. New Jersey: Person Prentice Hall.

Hean, S. (2009). The measurement of stereotypes in the evaluation of interprofessional education. In J. Jackson \& P. Blateau (Eds.), Innovation, Implementation and evaluation: the keys to unlocking InterProfessional Learning. Basingstoke, England: Palgrave Macmillan

Henseler, J., Ringle, C. M., \& Sarstedt, M. (2015). A new criterion for assessing discriminant validity in variance-based structural equation modeling. Journal of the Academy of Marketing Science, 43(1), 115-135.

Henseler, J., Ringle, C. M., \& Sinkovics, R. R. (2009). The use of partial least squares path modeling in international marketing. Advances in international marketing, 20, 277-319.

Hock, C., Ringle, C. M., \& Sarstedt, M. (2010). Management of multi-purpose stadiums: Importance and performance measurement of service interfaces. International Journal of Services Technology and Management, 14(2), 188-207.

Jussim, L., Nelson, T. E., Manis, M., \& Soffin, S. (1995). Prejudice, stereotypes, and labeling effects: Sources of bias in person perception. Journal of Personality and Social Psychology, 68(2), $228-246$

Kim, Y. Y. (1988). Communication and cross-cultural adaptation: An integrative theory. Clevedon, United Kingdom: Multilingual Matters.

Kim, Y. Y. (2001). Becoming intercultural: An integrative theory of communication and crosscultural adaptation. Thousand Oaks, CA: Sage.

Kline, R. B. (2011). Principles and practice of structural equation modeling. New York: Guilford Press.

Kwak, K. (1991). Second language learning in a multicultural society: A comparison between the learning of a dominant language and a heritage language. Queen's University, Kingston, Canada.

Lazarus, R. S., \& Folkman, S. (1984). Stress, coping and appraisal. New York: Springer.

Lee, J.-y., \& Ciftci, A. (2014). Asian international students' socio-cultural adaptation: Influence of multicultural personality, assertiveness, academic self-efficacy, and social support. International Journal of Intercultural Relations, 38(January), 97-105.

Lewin, K. (1951). Field theory in social science (Edited by Dorwin Cartwright.). New York: Harper and Brothers.

Li, A., \& Gasser, M. B. (2005). Predicting Asian international students' sociocultural adjustment: A test of two mediation models. International Journal of Intercultural Relations, 29(5), 561-576.

Lohmöller, J.-B. (1989). Latent Variable Path Modeling with Partial Least Squares. Heidelberg, Germany: Physica-Verlag.

Lovibond, P. F., \& Lovibond, S. H. (1995). The structure of negative emotional states: Comparison of the Depression Anxiety Stress Scales (DASS) with the Beck Depression and Anxiety Inventories. Behaviour research and therapy, 33(3), 335-343. 
Mahmud, Z., Amat, S., Rahman, S., \& Ishak, N. M. (2010). Challenges for international students in Malaysia: Culture, climate and care. Procedia-Social and Behavioral Sciences, 7, 289-293.

Ministry of Higher Education Malaysia. (2009). Laporan Statistik Pelajar. 2009. Retrieved 20 February, 2014, from http://www.mohe.gov.my/web_statistik/index.htm

Molinsky, A. (2007). Cross-cultural code-switching: The psychological challenges of adapting behavior in foreign cultural interactions. Academy of Management Review, 32(2), 622-640.

O'Sullivan, C. S., \& Durso, F. T. (1984). Effect of schema-incongruent information on memory for stereotypical attributes. Journal of Personality and Social Psychology, 47(1), 55-70.

PEMANDU. (2010). Economic transformation programme: A roadmap for Malaysia. Malaysia.

Porter, P., \& Vidovich, L. (2000). Globalization and higher education policy. Educational Theory, $50(4), 449-465$.

Ringle, C. M., Wende, S., \& Becker, J. M. (2014). SmartPLS 3.0. Retrieved from www.smartpls.com

Rosenberg, M. (1965). Society and the adolescent self-image. Princeton, NJ: Princeton University Press.

Safdar, S., Struthers, W., \& van Oudenhoven, J. P. (2009). Acculturation of Iranians in the United States, the United Kingdom, and the Netherlands A Test of the Multidimensional Individual Difference Acculturation (MIDA) Model. Journal of Cross-Cultural Psychology, 40(3), 468491.

Schloderer, M. P., Sarstedt, M., \& Ringle, C. M. (2014). The relevance of reputation in the nonprofit sector: the moderating effect of socio-demographic characteristics. International Journal of Nonprofit and Voluntary Sector Marketing, 19(2), 110-126.

Schultz, D., \& Schultz, S. (2004). A history of modern psychology. Belmont, CA: Wadsworth.

Sorrentino, R. M. (2013). Looking for B= f (P, E): The exception still forms the rule. Motivation and Emotion, 37(1), 4-13.

Sumer, S. (2009). International Students' Psychological and Sociocultural Adaptation in the United States. Counseling and Psychological Services Dissertations, Paper 34.

Sumer, S., Poyrazli, S., \& Grahame, K. (2008). Predictors of depression and anxiety among international students. Journal of Counseling \& Development, 86(4), 429-437.

Swaidan, Z., Vitell, S. J., Rose, G. M., \& Gilbert, F. W. (2006). Consumer ethics: the role of acculturation in U.S. immigrant populations. Journal of Business Ethics, 64(1), 1-16.

Tajfel, H., \& Turner, J. (1986). The social identity theory of intergroup behaviour. In W. Austin \& S. Worchel (Eds.), The social psychology of intergroup relations (pp. 7-24). Chicago: NelsonHall

Tonsing, K. N. (2013). Predictors of psychological adaptation of South Asian immigrants in Hong Kong. International Journal of Intercultural Relations, 37(2), 238-248.

Verbik, L., \& Lasanowski, V. (2007). International student mobility: Patterns and trends. World Education News and Reviews, 20(10), 1-16.

Wang, Y., \& Sun, S. (2009). Examining Chinese students' Internet use and cross-cultural adaptation: does loneliness speak much? Asian Journal of Communication, 19(1), 80-96.

Ward, C. (2004). Psychological theories of culture contact and their implications for intercultural training and interventions. In D. Landis, J. Bennett \& M. Bennett (Eds.), Handbook of Intercultural Training. Thousand Oaks, CA: Sage

Ward, C., \& Kennedy, A. (1994). Acculturation strategies, psychological adjustment, and sociocultural competence during cross-cultural transitions. International Journal of Intercultural Relations, 18(3), 329-343.

Ward, C., \& Kennedy, A. (1999). The measurement of sociocultural adaptation. International Journal of Intercultural Relations, 23(4), 659-677.

Yang, B., \& Clum, G. A. (1994). Life Stress, Social Support, and Problem-Solving Skills Predictive of Depressive Symptoms, Hopelessness, and Suicide Ideation in an Asian Student Population: A Test of a Model. Suicide and Life-Threatening Behavior, 24(2), 127-139.

Zhou, Y., Frey, C., \& Bang, H. (2011). Understanding of International Graduate Students' Academic Adaptation to a US Graduate School. International Education, 41(1), 76-96.

Zimet, G. D., Dahlem, N. W., Zimet, S. G., \& Farley, G. K. (1988). The Multidimensional Scale of Perceived Social Support. Journal of Personality Assessment, 52, 30-41. 